\title{
Estimation of baboon daily travel distances by means of point sampling - the magnitude of underestimation
}

\author{
Holger Sennhenn-Reulen ${ }^{1,2}$, Langhalima Diedhiou ${ }^{3}$, Matthias Klapproth ${ }^{1}$, and Dietmar Zinner ${ }^{1}$ \\ ${ }^{1}$ Cognitive Ethology Laboratory, German Primate Center, Leibniz-Institute for Primate Research, \\ Kellnerweg 4, 37077 Göttingen, Germany \\ ${ }^{2}$ Leibniz ScienceCampus "Primate Cognition”, German Primate Center/Leibniz Institute for Primate Research, \\ Kellnerweg 4, 37077 Göttingen, Germany \\ ${ }^{3}$ Direction Parc National du Niokolo-Koba, Tambacounda, Senegal \\ Correspondence to: Dietmar Zinner (dzinner@gwdg.de)
}

Received: 28 March 2017 - Revised: 29 May 2017 - Accepted: 2 June 2017 - Published: 10 July 2017

\begin{abstract}
Daily travel distance (DTD), the distance an animal moves over the course of the day, is an important metric in movement ecology. It provides data with which to test hypotheses related to energetics and behaviour, e.g. impact of group size or food distribution on DTDs. The automated tracking of movements by applying GPS technology has become widely available and easy to implement. However, due to battery duration constraints, it is necessary to select a tracking-time resolution, which inevitably introduces an underestimation of the true underlying path distance. Here we give a quantification of this inherent systematic underestimation of DTDs for a terrestrial primate, the Guinea baboon. We show that sampling protocols with interval lengths from 1 to 120 min underestimate DTDs on average by 7 to $35 \%$. For longer time intervals (i.e. 60, 90, $120 \mathrm{~min}$ ), the relative increase of deviation from the "true" trajectory is less pronounced than for shorter intervals. Our study provides first hints on the magnitude of error, which can be applied as a corrective when estimating absolute DTDs in calculations on travelling costs in terrestrial primates.
\end{abstract}

\section{Introduction}

Spatial information is crucial for many questions in ecological and behavioural research, e.g. species or resource distribution, habitat utilisation and estimates of home ranges or daily travel paths. The application of a satellite-supported global positioning system (GPS) has improved the collection and accuracy of spatial data (Kays et al., 2015), providing ecologists and behavioural biologists with opportunities to determine spatial patterns and test spatially explicit hypotheses. Similarly, the use of GPS has become more prevalent in primate field studies (Osborne and Glew, 2011; Sterling et al., 2013). Beside the determination of geographical positions of ecological objects or structures within a primate's home range - such as sleeping and resting sites, feeding patches or seed-dispersal events - spatial data have been used to estimate home ranges (position, shape and size), habitat utilisation, and daily travel paths and travel dis- tances. In primatology, the application of GPS collars indicated great potential particularly for semi-terrestrial primates in (semi-)open habitats (Markham and Altmann, 2008), but also for arboreal species (Stark et al., 2017).

Either animals can be equipped with a GPS device, and the respective positions will be collected automatically at preprogrammed intervals, or a researcher follows an animal and determines the positions using a handheld device (e.g. see Table 1). The GPS device consumes energy for every location fix, and thus battery life limits the number of position attempts or fixes a device can do. Programming fewer GPS fixes results in longer battery life but at the price of lower data density. It might not be a big problem if one is interested in the area an animal uses within a year, which one can probably estimate fairly well with just 2 or 3 fixes day ${ }^{-1}$ (Cagnacci et al., 2010). However, it can be problematic if one is interested in daily travel distance (DTD), where, optimally, a quasi-continuous recording of the travel path would be best, 
Table 1. A selection of GPS fixing intervals applied in primate and non-primate studies.

\begin{tabular}{|c|c|c|c|}
\hline Species & Sampling interval & Device & Reference \\
\hline Papio anubis & "Continuously" at $1 \mathrm{~Hz}$ & Collar & Strandburg-Peshkin et al. (2015) \\
\hline Chlorocebus & $15 \min$ & Collar & Isbell and Bidner (2016) \\
\hline Papio ursinus & $20 \mathrm{~min}$ & Collar & Hoffman and O'Riain (2012) \\
\hline Papio ursinus & $1 \mathrm{~h}$ & Collar & Pebsworth et al. $(2012 a, b)$ \\
\hline Papio cynocephalus & $1 \mathrm{~h}$ & Collar & Markham and Altmann (2008) \\
\hline Macaca fuscata & $1 \mathrm{~h}$ & Collar & Sprague et al. (2004) \\
\hline Nasalis concolor & $1 \mathrm{~h}$ & Collar & Stark et al. (2017) \\
\hline Papio ursinus & $3 \mathrm{~h}$ & Collar & Hoffman and O'Riain (2012) \\
\hline Rhinopithecus bieti & $2-5$ fixes day $^{-1}$ & Collar & Ren et al. (2008) \\
\hline Rhinopithecus bieti & $2-5$ fixes day $^{-1}$ & Collar & Ren et al. (2009) \\
\hline Gorilla beringei & $30 \mathrm{~s}$ & Handheld & Wright et al. (2015) \\
\hline Papio cynocephalus & $5 \mathrm{~min}$ & Handheld & Johnson et al. (2015) \\
\hline Papio ursinus & Average $9 \mathrm{~min}$ & Handheld & Bonnell et al. (2015) \\
\hline Chiropotes sagulatus & Average $10 \mathrm{~min}$ & Handheld & Gregory et al. (2014) \\
\hline Papio ursinus & $20 \mathrm{~min}$ & Handheld & Hoffman and O'Riain (2012) \\
\hline Macaca silenus & $30 \mathrm{~min}$ & Handheld & Santhosh et al. (2015) \\
\hline Rhinopithecus bieti & $30 \mathrm{~min}$ & Handheld & Grueter et al. (2008) \\
\hline Hoolock leuconedys & $30 \mathrm{~min}$ & Handheld & Sarma and Kumar (2016) \\
\hline Equus caballus & $5 \mathrm{~s}$ for 6.5 days & Collar & Hampson et al. (2010) \\
\hline Panthera tigris & $1-3 \mathrm{~h}$ & Collar & Naha et al. (2016) \\
\hline Capra hircus & $2 \mathrm{~h}$ & Collar & Chynoweth et al. (2015) \\
\hline Elephas maximus & $8 \mathrm{~h}$ & Collar & Alfred et al. (2012) \\
\hline Canis lupus & $0.25,1.5,2,6,12 \mathrm{~h}$ & Collar & Mills et al. (2006) \\
\hline
\end{tabular}

e.g. 1 fix s$^{-1}(1 \mathrm{~Hz})$. In many studies, a trade-off between long battery life for collecting data over a longer time period to estimate annual home ranges and a high data density to estimate DTD is sought. In particular the number of fixes per day used to estimate DTDs can influence the accuracy of the estimates and can make comparative studies within and between species difficult (e.g. Johnson et al., 2015).

Uncertainties in animal movement data, owing e.g. to sampling frequency, may strongly influence interpretations of tracking data (Bradshaw et al., 2007; Harris and Blackwell, 2013; Laube and Purves, 2011). As expected, in a number of studies it was shown that, as sampling intervals increase, the uncertainty of the behaviour between fixes increases; e.g. DTDs estimated from low sampling frequencies were significantly shorter than those based on higher sampling frequencies (Laundré et al., 1987; Mills et al., 2006; Reynolds and Laundré, 1990; Rowcliffe et al., 2012; Edelhoff et al., 2016). How, if at all, this effect can be corrected statistically or by modelling is an open question (Blackwell et al., 2016; Fleming et al., 2014a, b, 2016; Shamoun-Baranes et al., 2011). One way to mitigate these effects can be an empirical estimation of the magnitude of error one yields by applying different sampling frequencies.

In a study on range use of Guinea baboons (Papio papio) in the Niokolo-Koba National Park (Parc National du Niokolo-Koba, PNNK), Senegal, we equipped baboons with Tellus ultra-light GPS remote ultra-high-frequency (UHF) collars (Televilt, TVP Positioning AB, Lindesberg, Sweden; nowadays Followit AB). Since the main purpose of the application of GPS collars was to estimate home ranges of the baboons rather than an analysis of DTDs and since battery longevity was limited, we programmed the collars to take only $10 \mathrm{fix} \mathrm{day}^{-1}$ (seven fixes between 06:00 and 18:00 at $2 \mathrm{~h}$ intervals, and three fixes at night at 21:00, 00:00 and 03:00) but over a longer period (on average 10 months). Even with a sampling interval of $2 \mathrm{~h}$ and thus just seven location points per day (the night-time fixes were not used since the baboons remained mainly stationary during the night), it was possible to approximate DTDs which could at least be used for interindividual comparisons within the same population, given that the error in estimating DTDs was similar for all collared baboons. However, absolute DTDs were expected to be much longer than those approximations based on just seven location points (Fig. 1), making estimations on actual travelling costs unreliable and comparisons of DTDs with other studies problematic.

In our study we therefore aimed to estimate the magnitude of error when determining DTDs for Guinea baboons (Papio papio) by applying various sampling intervals instead of continuous tracking. For this we compared "true" DTDs with DTDs estimated by using 1, 2, 5, 10, 15, 30, 60, 90 and 120 min sampling intervals. The true DTD derived from direct, quasi-continuous GPS tracking of focal baboons; i.e. a baboon was followed by a researcher carrying a handheld 


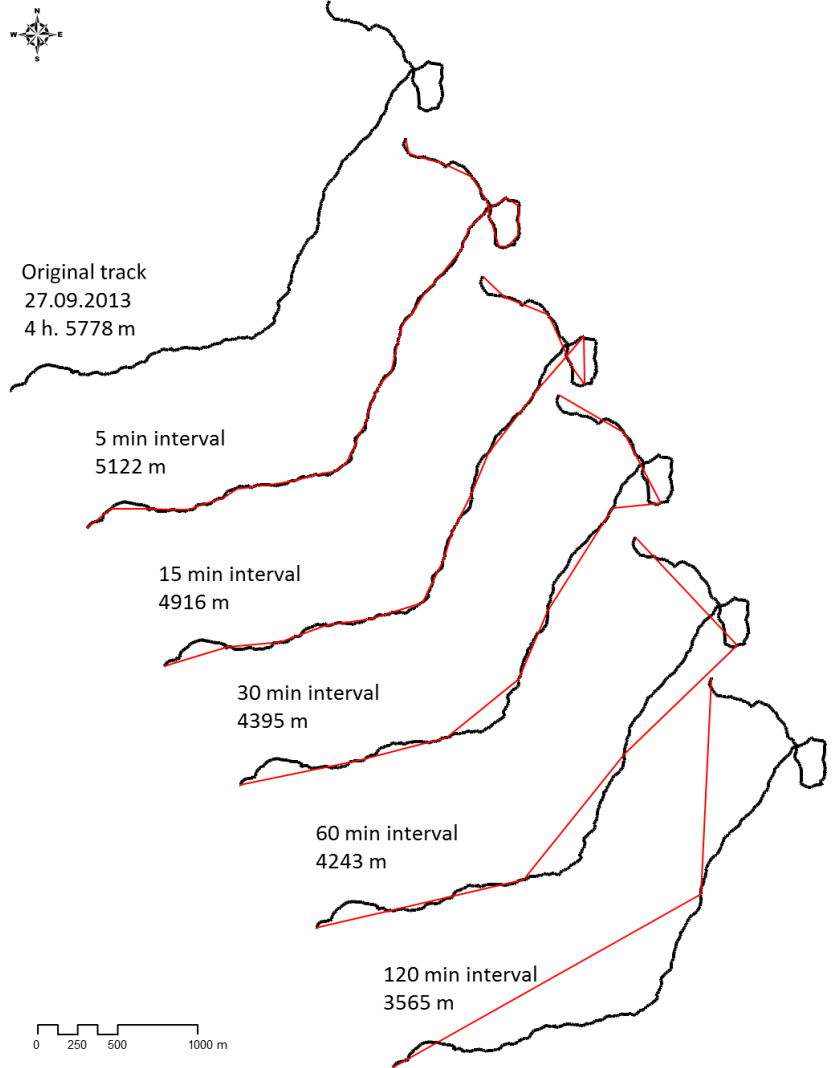

Figure 1. Example of a baboon track line (black) over $4 \mathrm{~h}$ and estimated travel distances if sampling is done applying different interval lengths (respective red lines).

GPS device recording a continuous track. Further, one can expect that if a baboon moves more or less in a straight line the error might be smaller than in cases when the baboons meander a lot (e.g. Postlethwaite and Dennis, 2013). We therefore explored which particular travel behaviours of the baboons resulted in a greater or smaller deviation from the true DTD.

\section{Methods}

\subsection{Study site and subjects}

The study was carried out in the Niokolo-Koba National Park at the research station of the German Primate Center in Simenti $\left(13^{\circ} 01^{\prime} 34^{\prime \prime} \mathrm{N}, 13^{\circ} 17^{\prime} 41^{\prime \prime} \mathrm{W}\right)$. The habitat consists of a forest-savannah mosaic with seasonally flooded grassland, dry deciduous forest and gallery forest along the Gambia River. The climate is characterised by a dry season from November until May and a rainy season from June until October.

The baboon community in Simenti comprises 350-400 individuals. They live in a multi-level society consisting of onemale units (OMUs), parties and gangs (Patzelt et al., 2014;
Goffe et al., 2016). The baboons were habituated to human observers, so that observations and follows could be done from less than $5 \mathrm{~m}$ distance.

We selected four males from different parties, and one of us (Langhalima Diedhiou) followed on foot one individual baboon at a time, keeping a distance of $5 \mathrm{~m}$ to the respective focal animal. The follows were repeated several times for each male (Table 2). The respective tracks were recorded with a handheld Garmin GPSMAP 62. Tracing set-up was "auto-normal". In sum we recorded $562 \mathrm{~h}$ tracks. In nine cases we experienced gaps in the continuous recording of the respective tracks (leg time $>60 \mathrm{~s}$ ). We deleted these nine tracks from our analyses.

\subsection{Statistical analysis}

\subsubsection{Deviation from true travel distance}

Using a GPS device, even a continuous track consists of a number of fixes, optimally with a very short sampling interval or leg time. Leg time is the delta between the time stamps of the two fixes bounding the leg (e.g. $1 \mathrm{~s}$ if the sampling frequency is $1 \mathrm{~Hz}$ ). However, since conditions are not always optimal, the real leg time varies and is most often larger than the targeted $1 \mathrm{~s}$ leg time. As a result, when we overlaid the continuous track with a 1 min sampling interval, for instance, the respective $1 \mathrm{~min}$ time stamps did not necessarily match with a fix from the GPS device. For instance, the closest time stamps can be at 57 or $62 \mathrm{~s}$ instead of $60 \mathrm{~s}$. Therefore we had to interpolate the tracks and re-discretise them.

We artificially re-discretised the original tracks with regular sampling intervals of 1, 2, 5, 10, 15, 30, 60, 90 and 120 min (shown on the $x$ axis of Figs. 3 and 4) by using linear interpolation between coordinates from the original tracks where necessary. This was achieved using the function "redisltraj" in the "adehabitatLT" R package (Calenge, 2006). The deviation from the original travel distance is the difference between the original travel distance and the travel distance of the re-discretised version.

To get to a relationship between the deviation from the original travel distance and the re-discretisation sampling interval duration, we fitted a Bayesian multilevel log-normal regression model using the Stan-based (Stan Development Team, 2015) R add-on package brms (Bürkner, 2017), with track index as grouping factor $\gamma_{i}$. The conditional mean of the deviation from the original travel distance $y$ across the rediscretisation sampling interval duration range of $t \in[1,120]$ was modelled as a $\frac{y}{-15}$ transformed response (log-normally distributed, therefore with a $\log _{e}$ link function) on the basis of the linear predictor $\beta_{0}+\beta_{1} \cdot t+\beta_{2} \cdot \log _{e}(t)+\gamma_{i}$, which leads to an improved expected predictive accuracy (based on the leave-one-out information criterion; Vehtari et al., 2016) in comparison to a set of other potential non-linear transformations, including a linear relationship, and power transformations of higher order. Section S1 in the Supplement gives 
Table 2. Temporal distribution of tracking periods. Tracking periods were either 4 or $2 \mathrm{~h}$ long. ID: individual baboon males; numbers in first horizontal line indicate hours of the day. T: tracking periods included in analysis; t: tracking periods excluded, because of gaps in the continuous tracking larger than $60 \mathrm{~s}$.

\begin{tabular}{|c|c|c|c|c|c|c|c|c|c|c|c|c|c|c|c|}
\hline ID & Date (dd.mm.уyуy) & 5 & 6 & 7 & 8 & 9 & 10 & 11 & 12 & 13 & 14 & 15 & 16 & 17 & 18 \\
\hline MST & 08.09 .2013 & & & $\mathrm{~T}$ & $\mathrm{~T}$ & $\mathrm{~T}$ & $\mathrm{~T}$ & & & & & & $\mathrm{~T}$ & $\mathrm{~T}$ & \\
\hline MST & 09.09 .2013 & & & $\mathrm{~T}$ & $\mathrm{~T}$ & $\mathrm{t}$ & $\mathrm{t}$ & & & & & & $\mathrm{T}$ & $\mathrm{T}$ & \\
\hline SNE & 10.09 .2013 & & & & $\mathrm{~T}$ & $\mathrm{~T}$ & & & & & & & & & \\
\hline JKY & 14.09 .2013 & & & & $\mathrm{~T}$ & $\mathrm{~T}$ & $\mathrm{~T}$ & $\mathrm{~T}$ & & & & & & & \\
\hline OSM & 15.09 .2013 & & & & $\mathrm{~T}$ & $\mathrm{~T}$ & & & & & & & & & \\
\hline MST & 16.09 .2013 & & & & $\mathrm{~T}$ & $\mathrm{~T}$ & & & & & & & & & \\
\hline SNE & 18.09 .2013 & & & $\mathrm{~T}$ & $\mathrm{~T}$ & $\mathrm{~T}$ & $\mathrm{~T}$ & & & & & & & & \\
\hline JKY & 19.09 .2013 & & & $\mathrm{t}$ & $\mathrm{t}$ & & & & & & & & & & \\
\hline MST & 20.09 .2013 & & & $\mathrm{t}$ & $\mathrm{t}$ & & $\mathrm{T}$ & $\mathrm{T}$ & & & & & $\mathrm{T}$ & $\mathrm{T}$ & \\
\hline SNE & 21.09 .2013 & & & $\mathrm{t}$ & $\mathrm{t}$ & $\mathrm{T}$ & $\mathrm{T}$ & & & & & & & & \\
\hline OSM & 23.09 .2013 & & & $\mathrm{~T}$ & $\mathrm{~T}$ & $\mathrm{~T}$ & $\mathrm{~T}$ & & & & & & & & \\
\hline OSM & 25.09 .2013 & & & & $\mathrm{~T}$ & $\mathrm{~T}$ & $\mathrm{~T}$ & $\mathrm{~T}$ & & & & & & & \\
\hline JKY & 26.09 .2013 & & & & $\mathrm{t}$ & $\mathrm{t}$ & $\mathrm{T}$ & $\mathrm{T}$ & & & & & & & \\
\hline SNE & 27.09 .2013 & & & $\mathrm{~T}$ & $\mathrm{~T}$ & $\mathrm{t}$ & $\mathrm{t}$ & & & & & & & & \\
\hline JKY & 28.09 .2013 & & & & $\mathrm{~T}$ & $\mathrm{~T}$ & $\mathrm{~T}$ & $\mathrm{~T}$ & & & & & & & \\
\hline OSM & 06.10 .2013 & & & $\mathrm{t}$ & $\mathrm{t}$ & $\mathrm{T}$ & $\mathrm{T}$ & & & & & & & & \\
\hline JKY & 07.10 .2013 & & & $\mathrm{~T}$ & $\mathrm{~T}$ & $\mathrm{~T}$ & $\mathrm{~T}$ & & & & & & & & \\
\hline JKY & 19.10 .2013 & & & $\mathrm{~T}$ & $\mathrm{~T}$ & $\mathrm{~T}$ & $\mathrm{~T}$ & & & & & & & & \\
\hline MST & 20.10 .2013 & & & $\mathrm{~T}$ & $\mathrm{~T}$ & $\mathrm{~T}$ & $\mathrm{~T}$ & & & & & & & & \\
\hline OSM & 21.10 .2013 & & & & $\mathrm{~T}$ & $\mathrm{~T}$ & & & & & & & $\mathrm{~T}$ & $\mathrm{~T}$ & \\
\hline SNE & 22.10 .2013 & & & $\mathrm{~T}$ & $\mathrm{~T}$ & $\mathrm{~T}$ & $\mathrm{~T}$ & & & & & & & & \\
\hline JKY & 23.10 .2013 & & & $\mathrm{~T}$ & $\mathrm{~T}$ & $\mathrm{~T}$ & $\mathrm{~T}$ & & & & & & $\mathrm{~T}$ & $\mathrm{~T}$ & \\
\hline OSM & 24.10 .2013 & & & $\mathrm{~T}$ & $\mathrm{~T}$ & $\mathrm{~T}$ & $\mathrm{~T}$ & & & & & & $\mathrm{~T}$ & $\mathrm{~T}$ & \\
\hline MST & 25.10 .2013 & & & $\mathrm{t}$ & $\mathrm{t}$ & $\mathrm{T}$ & $\mathrm{T}$ & & & & & $\mathrm{T}$ & $\mathrm{T}$ & & \\
\hline SNE & 26.10 .2013 & & & $\mathrm{t}$ & $\mathrm{t}$ & $\mathrm{T}$ & $\mathrm{T}$ & & & & & $\mathrm{T}$ & $\mathrm{T}$ & & \\
\hline JKY & 27.10 .2013 & & $\mathrm{~T}$ & $\mathrm{~T}$ & $\mathrm{~T}$ & $\mathrm{~T}$ & & & & & & $\mathrm{~T}$ & $\mathrm{~T}$ & & \\
\hline
\end{tabular}

more details on the applied statistical approach, as well as posterior mean and credible interval estimates for $\beta_{0} \beta_{1} \beta_{2}$.

\subsubsection{Hidden Markov model}

To be able to further quantify how the deviation from the original travel distance is related to moving velocity and turning-angle states, we fitted a hidden Markov model (Michelot et al., 2016). As an example, we performed this for a re-discretisation duration of $5 \mathrm{~min}$, which enables us to classify the underlying moving states on the basis of this coarsened information. This grid is still short enough - and therefore close enough to our original quasi-continuous sampling - to allow for making statements about the bias within these re-discretised intervals (too-long intervals would lead to mixing of underlying states; too-short intervals do not leave us with enough deviation from the original travel distances). We based this on the three following states: resting (no movement, state 1), slow velocities with uniformly distributed turning angles (state 2) and higher velocities with a higher likelihood for more straight movements (state 3). The parameters underlying these three states were fitted by a maximum-likelihood approach as implemented in the $\mathrm{R}$ package "moveHMM" (Michelot et al., 2016). We then compared the deviation from the original travel distance in metres per minute as introduced by re-discretisation of the original tracks on the $5 \mathrm{~min}$ grid, conditional on the reconstructed states by using the "Viterbi algorithm" on the basis of the hidden Markov model's results. Section S2 contains details on the states' parameterisations.

\section{Ethical approval}

All research adhered to the legal requirements of the countries from which samples were obtained. The study was carried out in compliance with the principles of the American Society of Primatologists for the ethical treatment of nonhuman primates (https://www.asp.org/society/resolutions/ EthicalTreatmentOfNonHumanPrimates.cfm). No animals were sacrificed or harmed for this study.

\section{Results}

\subsection{Distances travelled}

The database comprised $472 \mathrm{~h}$ tracks with 18073 fixes, resulting in 18026 legs. In $80.7 \%$ of cases the GPS device was 


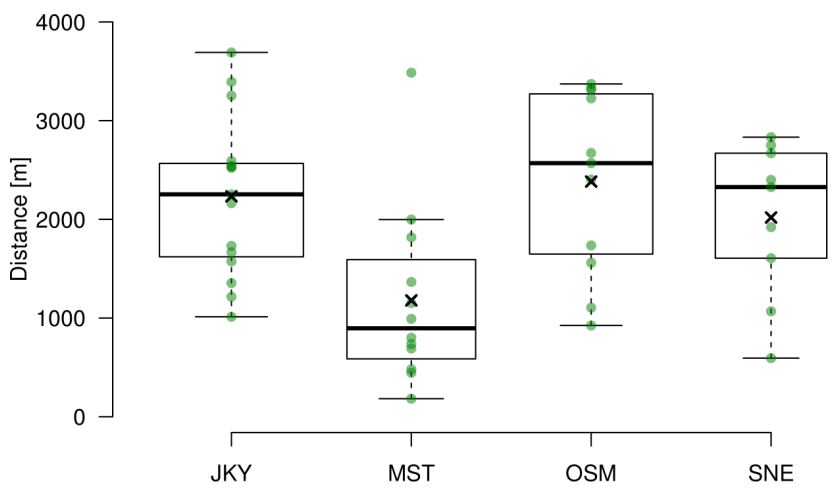

Figure 2. Inter- and intra-individual variation in distance travelled within $2 \mathrm{~h}$. Median as thick solid horizontal line; 1 st quartile $Q_{1}$ and 3rd quartile $Q_{3}$ as upper and lower box boundaries, respectively; whiskers calculated as upper whisker $=\min \left(\max (x), Q_{3}+\right.$ 1.5.IQR $)$ and lower whisker $=\max \left(\min (x), Q_{1}-1.5 \cdot \mathrm{IQR}\right)$, where $\mathrm{IQR}=\left|Q_{3}-Q_{1}\right| ;$ and mean as black cross. Kruskal-Wallis test: $H[3, N=47]=10.924 ; p=0.012 ; N_{\mathrm{JKY}}=15 ; N_{\mathrm{MST}}=12$; $N_{\mathrm{OSM}}=11 ; N_{\mathrm{SNE}}=9$.

able to fix a position in less than $30 \mathrm{~s}$. In only $0.6 \%$ of cases it took between 45 and $60 \mathrm{~s}$. Two-hour tracks lasted on average 2:00:06 h $(n=47 ; \mathrm{SD}=5 \mathrm{~s}$; $\min : 2: 00: 00 \mathrm{~h}$; $\max : 2: 00: 18 \mathrm{~h})$. Average leg time was $18.8 \mathrm{~s}(N=18026 ; \mathrm{SD}=11.0 \mathrm{~s}$; min: $1 \mathrm{~s}$; max: $60 \mathrm{~s})$. Within each leg the average distance covered by the baboons was $5.1 \mathrm{~m}(N=18026 ; \mathrm{SD}=5.5 \mathrm{~m}$; range: $0-37.0 \mathrm{~m})$.

The baboons travelled $1921 \mathrm{~m}$ within a $2 \mathrm{~h}$ track (median; range: $183-3691 \mathrm{~m} ; N=47$ ). However, among and within each subject there was considerable variation in speed of travelling and hence in distance covered within $2 \mathrm{~h}$ tracks (Fig. 2).

\subsection{Deviation from true distance}

The deviation from the real distance covered within a $2 \mathrm{~h}$ track increased the longer the sampling interval was (Fig. 3). If we applied a 1 min sampling interval, we already underestimated the distance by $6.3 \%$ on average (median). The deviation from the true distance increased to $32.3 \%$ (median) if we used $2 \mathrm{~h}$ sampling intervals. Considerable variation in underestimating the distance could be observed, which can reach in the extreme case more than $80 \%$ at $2 \mathrm{~h}$ sampling intervals.

There is strong support that the expected deviation from the true distance follows an exponential function (Fig. 4), indicating that the relative error increase is larger at shorter sampling intervals, as can be seen in Fig. 4 by the estimated expected error levelling off with increasing re-discretisation interval duration.

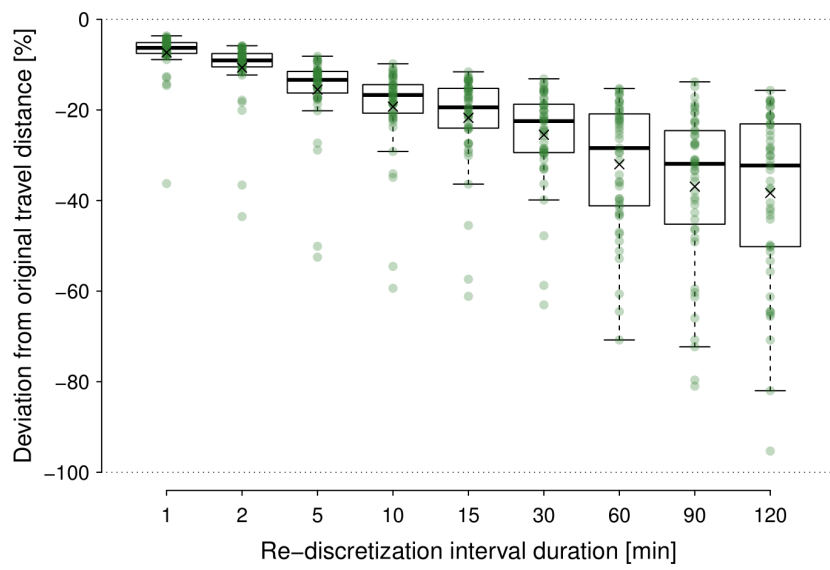

Figure 3. Deviation from original travel distance covered within $2 \mathrm{~h}$ (box plots illustrate the same descriptive statistics as described in the caption for Fig. 2), as revealed by applying different sampling intervals.

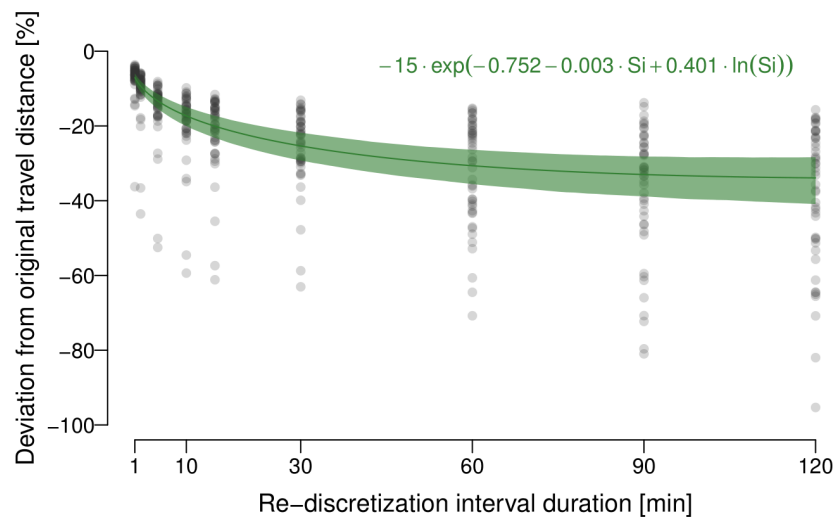

Figure 4. Expected deviation from the original travel distances (in $\%)$ conditional on re-discretisation interval duration (in minutes). The solid green line shows the estimated expectation (the functional form is described by the function as given on the top right of the figure); the green area shows a point-wise $99 \%$ uncertainty interval for this estimated conditional expectation.

\subsection{Impact of states on deviation}

The movement behaviour of the baboons - here categorised in three states: resting (no movement, state 1), slow velocities with uniformly distributed turning angles (state 2 ) and higher velocities with a higher density for more straight movements (state 3) - had a clear impact on the magnitude of error in estimating travel distances (Figs. 5 and 6). The deviation from true distance was of course smallest if the baboons did not move (stage 1) and largest if the baboons moved fast in a more or less straight direction. This appears counterintuitive at first glance but is explained by the much stronger consequences of even small turning angles at intervals with fast movement than at intervals with slow movement. 

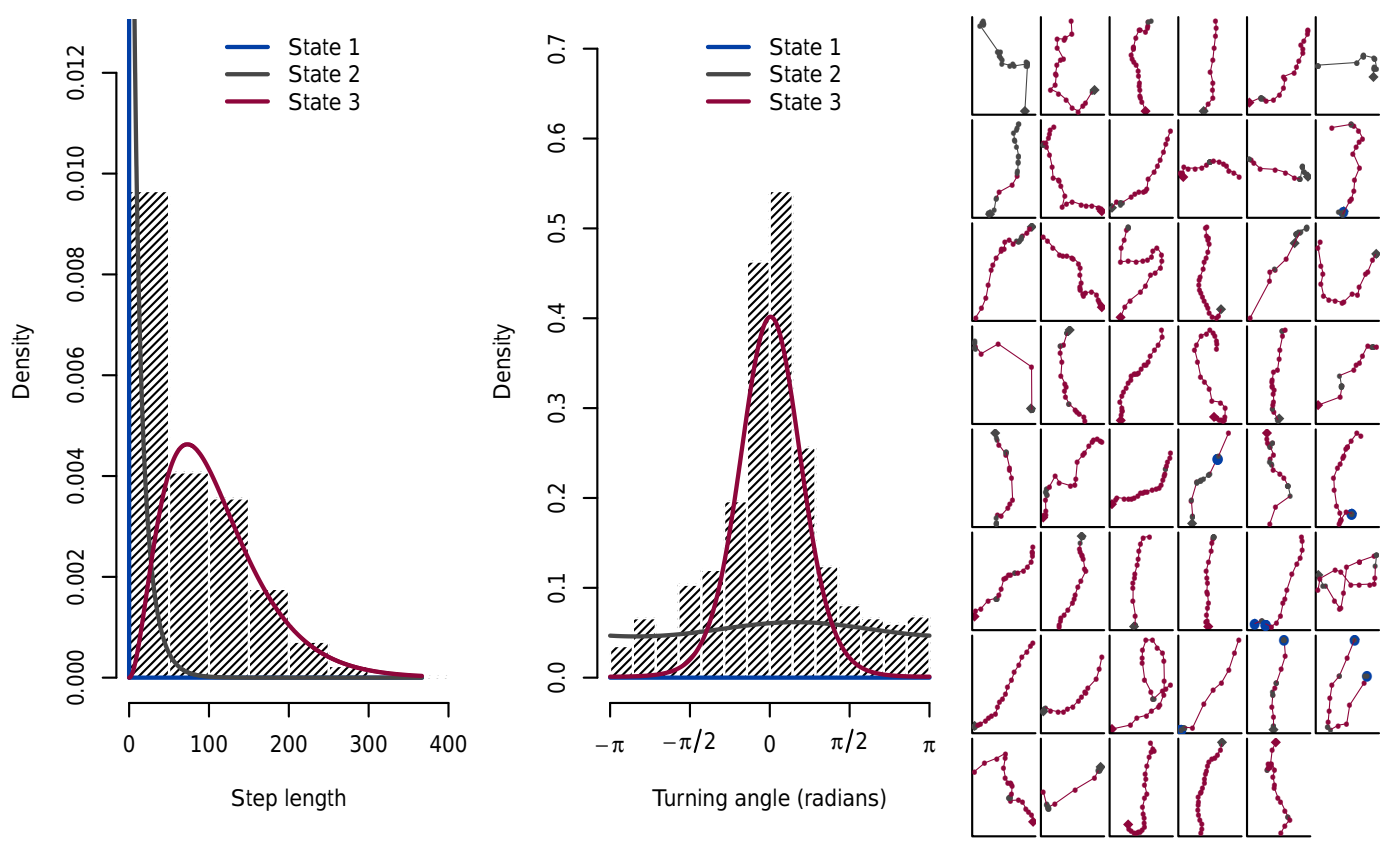

Figure 5. Results of the hidden Markov model estimation. Blue lines on the left and middle plots illustrate the densities for the "resting" state 1, dark grey lines show densities for state 2 (slow velocities, i.e. small step lengths per 5 min interval, approximately uniform distributed turning angles) and red lines illustrate the densities for state 3 (higher velocities and higher density for straight movements). The dashed histograms show the overall empirical distributions. The right figure shows the 47 tracks, coloured according to the states to which the Viterbi algorithm (based on the hidden Markov model results) categorised them ( $x$ and $y$ axes are scaled such that each track can be seen in the maximal graphical solution; i.e. they are not equally scaled across the 47 plots).

\section{Discussion}

Results of our analysis of the DTD of Guinea baboons met the general expectation: the higher the frequency of positions, the more trustworthy the movement paths (Nathan et al., 2008). The absolute average underestimate of DTDs was found to be less than $7 \%$ for $1 \mathrm{fix} \mathrm{min}^{-1}$ and less than $35 \%$ for 1 fix/120 min. However, it can reach up to a maximum of 30 and $90 \%$ if respective sampling frequencies of 1 fix $\min ^{-1}$ or 1 fix $120 \mathrm{~min}^{-1}$ are applied. The increase of deviation from true DTDs followed an exponential function, indicating that the average relative error increase is larger at shorter sampling intervals than at larger ones, which is in agreement with findings from Rowcliffe et al. (2012). For instance, whether, in the case of the Guinea baboons, we use a 90 or a 120 min sampling interval would not make a relevant difference in underestimating DTDs. At least for Guinea baboons we now have a reliable estimate of average underestimation of DTDs, which we can, for example, use as a correction when calculating absolute travel costs. We assume that similar magnitudes of underestimation of DTDs apply for other terrestrial primates, such as other baboon species.

The magnitude of error, however, is also dependent on the behaviour of the individuals under consideration. In the extreme, if an animal does not move over a long period, the true travelled distance is 0 and the deviation from the true value
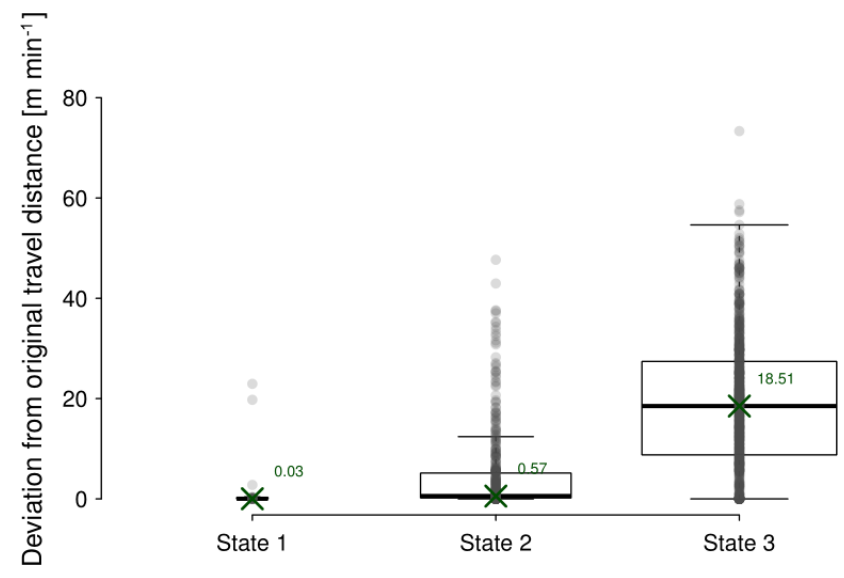

Figure 6. Deviation from original travel distance by the artificial 5 min sampling scheme, conditional on the states as estimated by the Viterbi algorithm applied on the hidden Markov model results shown in Fig. 5. Box plots illustrate the same descriptive statistics as described in the caption for Fig. 2, with values of the median conditional deviations given directly in the figure, and also illustrated by crosses.

also becomes 0 , irrespective of the length of the sampling interval. Similarly, it is very likely that the error remains small if an animal moves relatively slowly in a straight direction, whereas one can expect a large deviation if the animal moves 
quickly with a lot of meandering. In our study, we analysed the impact of movement behaviour exemplarily at a $5 \mathrm{~min}$ sampling interval. As expected, in state 1 (mainly resting) the deviation was minimal, whereas it increased minimally if the animal moved slowly (state 2) and increased more if it moved quickly (state 3). Since the spatial behaviour of baboons and other animals is often influenced by ecological condition (e.g. temporal and spatial distribution of food), one can expect season might affect step length and path tortuosity (Calenge et al., 2009; Owen-Smith et al., 2010).

Moreover, the time of day might play an additional role in shaping the characteristics of a travel path. In Chacma baboons (Papio ursinus), for example, Noser and Byrne (2010) found that their study group used two different strategies over the course of the day to exploit available fruit trees. In the early morning, the baboons showed a more goal-directed travel behaviour with linear travel routes and high movement speeds, whereas the baboons travelled more opportunistically (slower and less directly) during the rest of the day. DTDs can also vary among seasons if the spatial distribution of resources changes and forces individuals to adapt their DTDs (Hemingway and Bynum, 2005). If such temporal patterns in movement behaviour are significant in a species, the estimation of error in DTDs needs to be adapted to these patterns.

We were able to determine underestimations of DTDs in a terrestrial primate, the Guinea baboon, when applying different sampling intervals. The values of underestimation can be used as a corrective in estimations of absolute DTDs and travelling costs, which can make comparisons among different primate groups more reliable. Our analysis also showed, at least for terrestrial primates such as baboons, that there is no significant increase of underestimation beyond a sampling interval of $60 \mathrm{~min}(60,90,120 \mathrm{~min})$. As shown in Fig. 4, this mainly results from a weaker increase in underestimation for larger interval durations, and less from an increase in estimation uncertainty. Such a priori knowledge on underestimations of DTDs is important to inform researchers conducting GPS remote telemetry studies. Based on analyses such as ours, researchers can choose the "appropriate" sampling intensity in order to optimise the trade-off between sampling density and battery longevity.

We think that the overall magnitude of error, as found in our baboon study, will provide an estimate transferable also to other terrestrial or semi-terrestrial primate species. However, if the respective species show largely deviating movement behaviour, the magnitude of error will most likely change.

Data availability. Data are provided as Supplement S3.

\section{The Supplement related to this article is available online at https://doi.org/10.5194/pb-4-143-2017-supplement.}

Author contributions. DZ and MK designed the study. LD and MK collected the data in the field. HS-R did most of the data analyses. LD, MK, HS-R and DZ wrote the paper.

Competing interests. The authors declare that they have no conflict of interest.

Acknowledgements. We thank the Diréction des Parcs Nationaux and Ministère de l'Environnement et de la Protéction de la Nature de la République du Sénégal for permission to work in the Niokolo-Koba National Park (Attestation 0383/24/03/2009 and 0373/10/3/2012). In particular we thank the conservator of the Niokolo-Koba National Park for permitting and supporting this project research in the park. We also thank Vanessa Wilson for English language editing and two anonymous reviewers for their valuable comments. Funding was provided by the German Science Council DFG ZI 548/6-1 and the DAAD D/12/41834.

Edited by: Eberhard Fuchs

Reviewed by: two anonymous referees

\section{References}

Alfred, R., Ahmad, A. H., Payne, J., Williams, C., Ambu, L. N., How, P. M., and Goossens, B.: Home range and ranging behaviour of Bornean elephant (Elephas maximus borneensis) females, PLoS ONE, 7, e31400, https://doi.org/10.1371/journal.pone.0031400, 2012.

Blackwell, P. G., Niu, M., Lambert, M. S., and LaPoint, S. D.: Exact Bayesian inference for animal movement in continuous time, Methods Ecol. Evol., 7, 184-195, https://doi.org/10.1111/2041210X.12460, 2016.

Bonnell, T. R., Henzi, S. P., and Barrett, L.: Sparse movement data can reveal social influences on individual travel decisions, arXiv 1511.01536, 2015.

Bradshaw, C. J. A., Sims, D. W., and Hays, G. C.: Measurement error causes scale-dependent threshold erosion of biological signals in animal movement data, Ecol. Appl., 17, 628-638, https://doi.org/10.1890/06-0964, 2007.

Bürkner, P. C.: brms: An R Package for Bayesian Multilevel Models using Stan, J. Stat. Softw., in press, 2017.

Cagnacci, F., Boitani, L., Powell, R. A., and Boyce, M. S.: Animal ecology meets GPS-based radiotelemetry: a perfect storm of opportunities and challenges, Philos. T. R. Soc. B, 365, 2157-2162, https://doi.org/10.1098/rstb.2010.0107, 2010.

Calenge, C.: The package adehabitat for the R software: a tool for the analysis of space and habitat use by animals, Ecol. Model., 197, 516-519, https://doi.org/10.1016/j.ecolmodel.2006.03.017, 2006.

Calenge, C., Dray, S. and Royer-Carenzi, M.: The concept of animals' trajectories from a data analysis perspective, Ecol. Inform., 4, 34-41, https://doi.org/10.1016/j.ecoinf.2008.10.002, 2009.

Chynoweth, M. W., Lepczyk, C. A., Litton, C. M., Hess, S. C., Kellner, J. R., and Cordell, S.: Home range use and movement patterns of non-native feral goats in a tropical 
island montane dry landscape, PLoS ONE, 10, e0119231, https://doi.org/10.1371/journal.pone.0119231, 2015.

Edelhoff, H., Signer, J., and Balkenhol, N.: Path segmentation for beginners: an overview of current methods for detecting changes in animal movement patterns, Mov. Ecol., 4, 21, https://doi.org/10.1186/s40462-016-0086-5, 2016.

Fleming, C. H., Calabrese, J. M., Mueller, T., Olson, K. A., Leimgruber, P., and Fagan, W. F.: From fine-scale foraging to home ranges: A semivariance approach to identifying movement modes across spatiotemporal scales, Am. Nat., 183, E154-E167, https://doi.org/10.1086/675504, 2014a.

Fleming, C. H., Calabrese, J. M., Mueller, T., Olson, K. A., Leimgruber, P., and Fagan, W. F.: Non-Markovian maximum likelihood estimation of autocorrelated movement processes, Methods Ecol. Evol., 5, 462-472, https://doi.org/10.1111/2041210X.12176, 2014b.

Fleming, C. H., Fagan, W. F., Mueller, T., Olson, K. A., Leimgruber, P., and Calabrese, J. M.: Estimating where and how animals travel: an optimal framework for path reconstruction from autocorrelated tracking data, Ecology, 97, 576-582, https://doi.org/10.1890/15-1607.1, 2016.

Goffe, A. S., Zinner, D., and Fischer, J.: Sex and friendship in a multilevel society: behavioural patterns and associations between female and male Guinea baboons, Behav. Ecol. Sociobiol., 70, 323-336, https://doi.org/10.1007/s00265-015-2050-6, 2016.

Gregory, T., Mullett, A., and Norconk, M. A.: Strategies for navigating large areas: A GIS spatial ecology analysis of the bearded saki monkey, Chiropotes sagulatus, in Suriname, Am. J. Primatol., 76, 586-595, https://doi.org/10.1002/ajp.22251, 2014.

Grueter, C. C., Li, D., van Schaik, C. P., Ren, B., Long, Y., and Wei, F.: Ranging of Rhinopithecus bieti in the Samage Forest, China. I. Characteristics of range use, Int. J. Primatol., 29, 1121-1145, https://doi.org/10.1007/s10764-008-9299-9, 2008.

Hampson, B. A., De Laat, M. A., Mills, P. C., and Pollitt, C. C.: Distances travelled by feral horses in "outback" Australia, Equine Vet. J., 42, 582-586, https://doi.org/10.1111/j.20423306.2010.00203.x, 2010.

Harris, K. J. and Blackwell, P. G.: Flexible continuous-time modelling for heterogeneous animal movement, Ecol. Modell., 255, 29-37, https://doi.org/10.1111/2041-210X.12460, 2013.

Hemingway, C. A. and Bynum, N.: The influence of seasonality on primate diet and ranging, in: Seasonality in Primates Studies of Living and Extinct Human and Non-Human Primates, edited by: Brockman, D. K. and van Schaik, C. P., Cambridge University Press, Cambridge, 57-104, 2005.

Hoffman, T. S. and O'Riain, M. J.: Troop size and human-modified habitat affect the ranging patterns of a chacma baboon population in the Cape Peninsula, South Africa, Am. J. Primat., 74, 853863, https://doi.org/10.1002/ajp.22040, 2012.

Isbell, L. A. and Bidner, L. R.: Vervet monkey (Chlorocebus pygerythrus) alarm calls to leopards (Panthera pardus) function as a predator deterrent, Behaviour, 153, 591-606, 2016.

Johnson, C., Piel, A. K., Forman, D., Stewart, F. A., and King, A. J.: The ecological determinants of baboon troop movements at local and continental scales, Mov. Ecol., 3, 14, https://doi.org/10.1186/s40462-015-0040-y, 2015.

Kays, R., Crofoot, M., Jetz, W., and Wikelski, M.: Terrestrial animal tracking as an eye on life and planet, Science 348, 1222, https://doi.org/10.1126/science.aaa2478, 2015.
Laube, P. and Purves, R. S.: How fast is a cow? Crossscale analysis of movement data, T. GIS, 15, 401-418, https://doi.org/10.1111/j.1467-9671.2011.01256.x, 2011.

Laundré, J. W., Reynolds, T. D., Knick, S. T., and Ball, I. J.: Accuracy of daily point relocations in assessing real movement of radio-marked animals, J. Wildlife Manage., 51, 937-940, https://doi.org/10.2307/3801763, 1987.

Markham, A. C. and Altmann, J.: Remote monitoring of primates using automated GPS technology in open habitats, Am. J. Primatol., 70, 495-499, https://doi.org/10.1002/ajp.20515, 2008.

Michelot, T., Langrock, R., and Patterson, T. A.: moveHMM: an R package for the statistical modelling of animal movement data using hidden Markov models, Methods Ecol. Evol., 7, 13081315, https://doi.org/10.1111/2041-210X.12578, 2016.

Mills, K. J., Patterson, B. R., Murray, D. L., and Bowman, J.: Effects of variable sampling frequencies on GPS transmitter efficiency and estimated wolf home range size and movement distance, Wildlife Soc. B., 34, 1463-1469, https://doi.org/10.2193/00917648(2006)34[1463:EOVSFO]2.0.CO;2, 2006.

Naha, D., Jhala, Y. V., Qureshi, Q., Roy, M., Sankar, K., and Gopal, R.: Ranging, activity and habitat use by tigers in the mangrove forests of the Sundarban, PLoS ONE, 11, e0152119, https://doi.org/10.1371/journal.pone.0152119, 2016.

Nathan, R., Getz, W. M., Revilla, E., Holyoak, M., Kadmon, R., Saltz, D., and Smouse, P. E.: A movement ecology paradigm for unifying organismal movement research, P. Natl. Acad. Sci. USA, 105, 19052-19059, https://doi.org/10.1073/pnas.0800375105, 2008.

Noser, R. and Byrne, R. W.: How do wild baboons (Papio ursinus) plan their routes? Travel among multiple high-quality food sources with inter-group competition, Anim. Cogn., 13, 145155, https://doi.org/10.1007/s10071-009-0254-8, 2010.

Osborne, P. E. and Glew, L.: Geographical information systems and remote sensing, in: Field and Laboratory Methods in Primatology, edited by: Setchell, J. M. and Curtis, D. J., Cambridge University Press, Cambridge, 69-89, 2011.

Owen-Smith, N., Fryxell, J. M., and Merrill, E. H.: Foraging theory upscaled: the behavioural ecology of herbivore movement, Philos. T. R. Soc. B, 365, 2267-2278, https://doi.org/10.1098/rstb.2010.0095, 2010.

Patzelt, A., Kopp, G. H., Ndao, I., Kalbitzer, U., Zinner, D., and Fischer, J.: Male tolerance and male-male bonds in a multilevel primate society, P. Natl. Acad. Sci. USA, 111, 14740-14745, https://doi.org/10.1073/pnas.1405811111, 2014.

Pebsworth, P. A., Morgan, H. R., and Huffman, M. A.: Evaluating home range techniques: use of Global Positioning System (GPS) collar data from chacma baboons, Primates, 53, 345355, https://doi.org/10.1007/s10329-012-0307-5, 2012a.

Pebsworth, P. A., MacIntosh, A. J. J., Morgan, H. R., and Huffman, M. A.: Factors influencing the ranging behavior of chacma baboons (Papio hamadryas ursinus) living in a human-modified habitat, Int. J. Primatol., 33, 872-887, https://doi.org/10.1007/s10764-012-9620-5, 2012b.

Postlethwaite, C. M. and Dennis, T. E.: Effects of temporal resolution on an inferential model of animal movement, PLoS ONE, 8, e57640, https://doi.org/10.1371/journal.pone.0057640, 2013.

Ren, B., Li, M., Long, Y., Grueter, C. C., and Wei, F.: Measuring daily ranging distances of Rhinopithecus bieti via a Global Positioning System collar at Jinsichang, China: a 
methodological consideration, Int. J. Primatol., 29, 783-794, https://doi.org/10.1007/s10764-008-9251-z, 2008.

Ren, B., Li, M., Long, Y., and Wei, F.: Influence of day length, ambient temperature, and seasonality on daily travel distance in the Yunnan snub-nosed monkey at Jinsichang, Yunnan, China, Am. J. Primatol., 71, 233-241, https://doi.org/10.1002/ajp.20641, 2009.

Reynolds, T. D. and Laundre, J. W.: Time intervals for estimating pronghorn and coyote home ranges and daily movements, J. Wildlife Manage., 54, 316-322, https://doi.org/10.2307/3809049, 1990.

Rowcliffe, J. M., Carbone, C., Kays, R., Kranstauber, B., and Jansen, P. A.: Bias in estimating animal travel distance: the effect of sampling frequency. Methods Ecol. Evol., 3, 653-662, https://doi.org/10.1111/j.2041-210X.2012.00197.x, 2012.

Santhosh, K., Kumara, H. N., Velankar, A. D., and Sinha, A.: Ranging behavior and resource use by lion-tailed macaques (Macaca silenus) in selectively logged forests, Int. J. Primatol., 36, 288310, https://doi.org/10.1007/s10764-015-9824-6, 2015.

Sarma, K. and Kumar, A.: The day range and home range of the eastern hoolock gibbon Hoolock leuconedys (Mammalia: Primates: Hylobatidae) in Lower Dibang Valley District in Arunachal Pradesh, India, J. Threat. Taxa, 8, 8641-8651, https://doi.org/10.11609/jott.2739.8.4.8641-8651, 2016.

Shamoun-Baranes, J., van Loon, E. E., Purves, R. S., Speckmann, B., Weiskopf, D., and Camphuysen, C. J.: Analysis and visualization of animal movement, Biol. Lett., 8, 6-9, https://doi.org/10.1098/rsbl.2011.0764, 2011.

Sprague, D. S., Kabaya, H., and Hagihara, K.: Field testing a global positioning system (GPS) collar on a Japanese monkey: reliability of automatic GPS positioning in a Japanese forest, Primates, 45, 151-154, https://doi.org/10.1007/s10329-003-0071-7, 2004.
Stan Development Team: Stan: A C ++ Library for Probability and Sampling, Version 2.10.0, available at: http://mc-stan.org/ (last access: 1 July 2016), 2015.

Stark, D. J., Vaughan, I. P., Ramirez Saldivar, D. A., Nathan, S. K. S. S., and Goossens, B.: Evaluating methods for estimating home ranges using GPS collars: A comparison using proboscis monkeys (Nasalis larvatus), PLoS ONE, 12, e0174891, https://doi.org/10.1371/journal.pone.0174891, 2017.

Sterling, E. J., Bynum, N., and Blair, M. E. (Eds.): Primate Ecology and Conservation, A Handbook of Techniques, Oxford University Press, Oxford, 2013.

Strandburg-Peshkin, A., Farine, D. R., Couzin, I. D., and Crofoot, M. C.: Shared decision-making drives collective movement in wild baboons, Science, 348, 1358-1361, https://doi.org/10.1126/science.aaa5099, 2015.

Vehtari, A., Gelman, A., and Gabry, J.: Practical Bayesian model evaluation using leave-one-out cross-validation and WAIC, Stat Comput., 27, 1413, https://doi.org/10.1007/s11222-016-9696-4, 2016.

Wright, E., Grueter, C. C., Seiler, N., Abavandimwe, D., Stoinski, T. S., Ortmann, S., and Robbins, M. M.: Energetic responses to variation in food availability in the two mountain gorilla populations (Gorilla beringei beringei), Am. J. Phys. Anthropol., 158, 487-500, https://doi.org/10.1002/ajpa.22808, 2015. 